\title{
Information architecture
}

\author{
Tools for cutting-edge Web developers
}

by Rob Withers, Rob Casson, Aaron Shrimplin, and Katherine C. Adams

W hen the Web first emerged, Web sites consisted of relatively small collections of static, text-only data. The complexity of today's Web sites reflects powerful new tools for developing and managing them. Scripting languages enable Web developers to manage large amounts of data and create customizable interfaces that respond to user needs, while information architecture techniques ensure that Web users quickly and efficiently locate information.

The core of information architecture is Web site navigation, labeling/naming schemes, and Web site structure. Information architects determine the functional and conceptual building blocks of a site. Unlike Web designers who are concerned with typeface, graphics, and other particulars of constructing an interface, information architects create organizational and navigational structures that help people access information.

\section{Associations and centers}

- American Society for Information Science. This Web site offers a variety of resources for information architects, includ- ing a list of conferences and events, a jobline, a schedule of nationwide continuing education courses, and an online bookstore. $A C$ cess: http://www.asis.org/.

- The American Society of Indexers (ASI). This site is intended for those who index print and digital resources. ASI offers both general information on indexing and materials of special interest to those who index digital materials. Access. http://www.asindexing. org/index.html.

- The Argus Center for Information Architecture. Sponsored by Argus Associates, the leading Information Architecture firm in the United States (http://argus-inc.com/), this site manages a collection of links, posts original research articles, and lists seminars, events, and conferences of interest to the information architecture community. Access: http://argus-acia.com/.

\section{Electronic lists \\ - Information Architecture Listserv. Sponsored by American Society for Informa- tion Science (ASIS), this electronic list grew out of the ASIS Summit 2000 conference, De-}

\section{About the authors}

Rob Withers, Rob Casson, and Aaron Shrimplin are electronic information services librarians at Miami University, e-mail: rwithers@lib.muohio.edu, rcasson@lib.muohio.edu, and aaron@lib.muohio.edu; and Katherine C. Adams is information architect, Mohomine, e-mail:kadams@mohomine.com 
fining Information Architecture, held in Boston, April 8-9, 2000. The postings are often thought provoking and instructive. Access: www.asis.org/Conferences/Summit2000/ Information_Architecture/listserv.html.

- InfoDesign Listserv. A moderated, lowvolume electronic list that functions as a forum for information design issues. Participants discuss how to present visual information so that it is effective, efficient, and attractive Access: http://list.design-inst.nl/mailman/ listinfo/infodesign.

\section{Tutorials and general guides}

- Information Architecture Tutorial. John Shiple, an information architect from Venice, California, offers a concise, five-step guide to the basics of information architecture. Access: http://hotwired.lycos.com/ webmonkey/design/site_building/tutorials/ tutorial1.html

- Yale's Web Style Guide: Site Design. This chapter on site design is part of a larger electronic text on basic principles of Web site design. It includes a wonderful analysis of hierarchical Web site construction and introduces the important concept of "chunking information." Access: http:// info.med.yale.edu/caim/manual/sites/ site_design.html.

- Use it.com: Jacob Nielsen's Web Site. This site by the highly respected Nielsen, former Web site usability guru at Sun Microsystems, offers a wealth of information on how to construct Web sites that place user's needs front and center. Of special note is Nielsen's "Alertbox" column that began in 1995. Access: http://www.useit.com/.

\section{Critiques of Web sites}

- Deconstructing ... This column from the electronic journal Internet World offers critiques of some of the most prominent sites on the Web by a rotating group of designers and information architects. Access: http:// www.internetworld.com/print/decon/.

- A Closer Look: Critical Reviews of Corporate Websites. Louis Rosenfeld, a noted information architect, sizes up the Web sites of large corporations in this engaging series of essays. Access; http://webbusiness. cio.com/archive/closer.html.

- Critique of the Week. The column from the electronic journal CNET Builder.com ex- amines a variety of Web sites: e-commerce, e-journals, vertical portals, and entertainment sites. Written from a Web designer's point of view, these critiques are highly informative. Access: http://www.builder.com/Graphics/ Critique/index.html.

- Vincent Flanders' Web Pages that Suck.com. This site takes an amusing look at bad web site design. Although the critiques are written from the point of view of a Web designer, this site is chock-a-block with organizational and navigational examples to avoid. Access: http://www.websitesthatsuck.com/.

\section{Examples to follow}

- The Argus Clearinghouse. Founded in 1993 by students from the University of Michigan's Library and Information Studies Program, this site has gained fame as a topical guicle to Internet resources. Currently maintained by Argus Associates, this Web site is an excellent source of examples to follow. Access: http://www. clearinghouse.net/

\section{Argus Clearinghouse}

\section{Electronic journals}

- Web Review: Cross-Training for Web

Teams. This online journal is a superior resource for lively, informative articles. Access: http://www.webreview.com/.

- Internetworking. Sponsored by the Internet Technical Group, this site offers scholarly yet pragmatic essays on a wide range of topics, such as user interface design, human computer interaction, etc. $A c$ cess: http://www.sandia.gov/itg/newsletter/ newsletter.html

\section{Webliographies}

- Usable Web: 791 Links About Web Usability. This site has a wonderfully comprehensive collection of links to resources about Web usability testing, navigation, Web site design, technology, etc. Access: http://usableweb.com/.

- jig.net. Jig.net has a well-organized collection of links maintained by

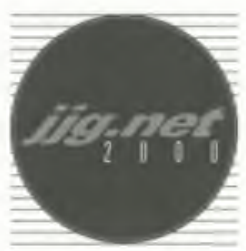


Jesse James Garrett, an information architect in. San Francisco. Access: http://www.jjg.net/ia/.

- Info. Design Information Architecture Resources. Sponsored by an information architecture firm, this is a carefully selected list of links on knowledge management, Web usability testing, navigation, writing for the Web, and more. Access: http:// www.infodn.com/iares-ia.shtml.

\section{Dynamic scripting languages}

Scripting languages such as PHP or cold Fusion can:

- develop interfaces that allow librarians who are not proficient with HTML to create and edit dynamically generated Web pages or catalogs;

- create Web pages that enable users to access tab-delimited data from outside sources, including metadata extracted from online catalogs and data sets available from commercial providers;

- generate interactive Web pages that adapt to the user's browser software or enable users to create customized interfaces; and

- facilitate usability studies by providing statistical information about each link.

While some languages are proprietary, many are also open source, ensuring that applications are readily available at no cost.

\section{Mailing lists/discussion}

\section{General}

- Web4lib. This list is a forum to foster the discussion of issues related to the creation and management of library-based Web servers and clients. Although this is a hightraffic list, there are frequent discussions of dynamic scripting languages. Discussion focuses more on selecting languages and developing projects than on specific scripting difficulties. Access: http://sunsite berkeley. edu/Web4Lib/archive.html.

\section{PHP related lists:}

- php-general@lists.php.net. This is the main, unmoderated, high-volume list for all things related to PHP scripting. Before posting to this list, people should make sure that there is not a more specific forum for their topic. Available as individual messages or digested.

- php-db@lists.php.net. This is a list for PHP questions regarding the language's abili- ties to interface with various database products. Relatively low-traffic.

- php-windows@lists.php.net. This is the list for users of PHP on various Windows platforms (NT, 2000, 98, etc.). Others available from the Web site at http://www.php.net/ support.php.

\section{postgresql lists}

- pgsql-admin@postgresql.org

- pgsql-sql@postgresql.org

- pgsql-novice@postgresql.org

Others available from the Web site at http://www.postgresql.org/lists/all-lists.html.

mysql lists

- mysql@lists.mysql.com

- win32@lists.mysql.com

\section{General resources for scripting}

- Database Enabled Websites Tutorial.

While very Linux/Apache/PHP/MySQL-oriented, this tutorial outlines how to install and get started with building dynamic and database-driven Web sites. Included are a working example of a guestbook application and documented source code. Instructions for installation are provided for two of the most popular flavors of Linux, Debian and Redhat. Access: http://www.awtrey.com/ support/dbeweb/

- Freshmeat. Although not focused on Web-based services, Freshmeat should be a first stop for anyone beginning to think about enhancing their Internet presence. Freshmeat is a directory to all kinds of server and desktop software, with a slant toward UNIX-type systems. Check here before reinventing the wheel; people can often find programs that will suit their needs and programming language requirements, and most everything at Freshmeat will be Open Source. Access: http://www.freshmeat.net.

- Webmonkey. People thinking about creating a database-driven Web site, check out Graeme Merrall's PHP/MySQL Tutorial. In addition to articles on MySQL and PHP, articles and tutorials on ColdFusion and ASP are available, as well. Access: http:// hotwired.lycos.com/webmonkey/.

- Webreview. (see above) This is another good site for articles about database-driven Web pages. Access: http://www. webreview.com/. 


\section{Open Source scripting resources}

- Devshed. Devshed is an excellent site for articles and tutorials on Open Source Web technologies. Tutorials are aimed at getting novice programmers up to speed on using PHP and MySQL as Web development tools. Articles range from "Website Database $\mathrm{Ba}$ sics with PHP and Mysql" to "Building an ECommerce Site." Be sure to check out the PHP 101 series. Access: www devshed.com.

- Mod_perl. Perl and the Apache Web servers have been some of the most versatile tools for building Web-based services, and mod_perl aims to more closely integrate the two. Embperl (http://perl.apache.org/ embperl/) is a module that allows developers to embed Perl directly into HTML pages, bringing the full power of Perl to Web development, including sites with database backends. Most of Embperl's strengths come from the strong base Perl itself provides, and is often the choice of experienced Perl programmers who don't want to learn a new language. Access: http://perl.apache.org.

- MySQL. MySQL is a good choice for Web developers who wish to begin working with scripting languages and relational databases. While it is reliable and quite fast, it lacks some of the more advanced SQL features of competitors like Oracle and PostgreSQL. MySQL is available for most UNIX, Windows, and OS/2 systems, and is covered by an Open Source licensing agreement. Access: http://www.mysql.com.

- Oss4lib-Open Source Systems for Libraries. It goes without saying that libraries should be partners in the Open Source movement. Oss ́lib is committed to maintaining a listing of free source movement by maintaining a listing of free software and systems designed for libraries. People who get the "PHP bug" should submit their code to the list. Also take a look at some of the projects that are already done, including a PHP Book Loan program. Access: http://www.oss4lib.org.

- PHP Builder. A PHP community site with articles covering introductory issues and more advanced and interesting applications of PHP. Many user-initiated forums contain tips and tricks from some of the foremost developers of PHP. Access: http://www. phpbuilder.com.

- PHP: Hypertext Preprocessor. PHP is a server-side scripting language available for
UNIX and Windows systems. It can be embedded directly into HTML tags and features

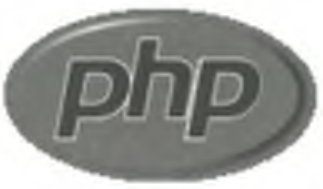
the ability to interface with database products like MySQL, PostgreSQL, Oracle, MS Access, and many others. The main site links to a complete annotated manual online, source code downloads, and links to outside resources. It is Open Source, and is becoming a first choice over alternative technologies like ColdFusion and ASP/VBScript. Access: http://woww.php.net.

- PostgresQL. PostgreSQL is an Open Source relational database management system that supports more advanced features of Structured Query Language (SQL) than MySQL, such as subqueries, transaction processing, and triggers. PostgreSQL is available for most UNIX-type systems, with a port to WindowsNT appearing more recently. Access: http://www.postgresql.org.

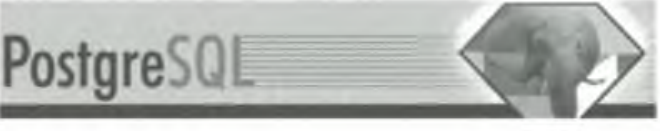

- Zope. Zope is an ongoing effort to provide an Open Source content management and portal system. It is written in Python and $\mathrm{C}$, and there are efforts to add Perl support in the future. Site templates can be used to ensure consistency across the site, with content that can be edited through a Web-based interface. While it may not be as flexible as PHP or Embperl, Zope provides an option for sites that wish to provide some dynamic functionality, but don't want to "roll their own" solution. Access: http://www.zope. org.

\section{Proprietary scripting languages}

- ColdFusion. This site has had great name recognition in the field of databaseenabled Web sites for many years now. It is a viable option for those who wish to buy an out-of-the-box solution to delivering existing databases to end-users. It features an HTMLembeddable syntax, much like PHP and Embperl. There are many product levels to choose from, with support for Windows, Linux, Solaris, and HP-UX. Access: http:// www.allaire.com/products/coldfusion/. 


\section{Are some of your periodicals having an identity crisis?}

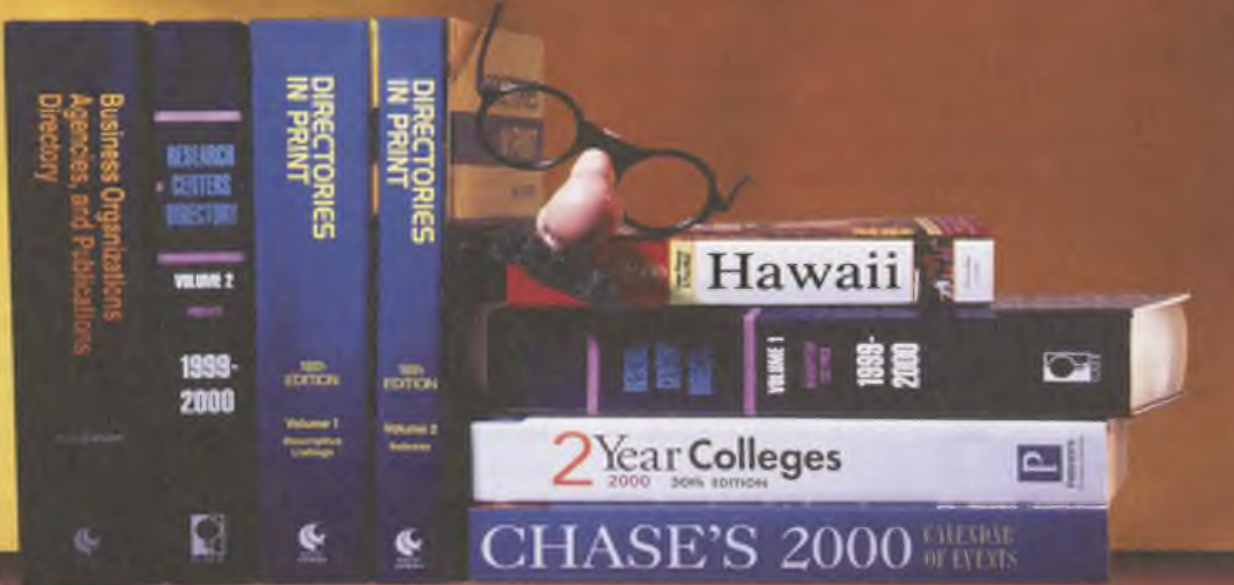

\section{Many standing order titles are books, but they are also serial publications}

available from EBSCO Subscription Services, a respected name in the serials industry.

EBSCO handles more than 20,000 titles classified by publishers as "standing orders." And we provide the same superior customer service for these titles as for traditional subscription orders.

Benefits of ordering these titles through EBSCO include:

- consolidation of all subscription orders with a single vendor

- a Customer Service Representative dedicated to your account

- a number of Special Reports that provide data useful in serials management and collection development.

To request more information about EBSCO's standing order services, contact the EBSCO Regional Office nearest you, visit our Web site, www.ebsco.com, and click on the "free trials/demos" link, or complete and mail the business reply card at the back of this catalog.

P.O. Box 1943 • Birmingham, AL 35201-1943 (205) $991-6600 \cdot \operatorname{Fax}(205) 995-1636$ http://www.ebsco.com

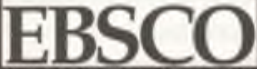

SUEGCRाPTON SFRVICES

A part of the EBSCO luformation Services sroup 